s)lid bodies, and yet retain the red bloot corpuscles even under great increase of pressure.

M. E. LEFEVRE is engaged upon a monograph of the species of the genus Clythra, inhabiting Europe and its confines (including the Mediterranean region). As many new species have been discovered, especially in Algeria and the East, since the publication of Lacordaire's memoir in 1848 , M. Lefèvre will be thankful for the loan of specimens of new or rare species, and for any information as to their geographical distribution. M. Lefèvre's address is 28, Rute Constantine, Paris-Plaisance.

We quote the following from the Scotsman, of May 2 :- "A correspondent writes: "In Inverleith Row on Saturday night, exactly at a quarter-past eleven o'clock, my attention was attracterl by a sudden and strange brightness overspreading everything around. Instinctively turning my eyes upwards, a grand sight met my gaze. A meteor of remarkable size, brilliancy, and distinctness, was seen shooting from the heavens, from about the zenith, and descending earthwards in a southerly direction. The form of this interesting object seemed elliptical, and it was of a bright yellow hue. It had a clearly-defined apex or point, which was of a deep red colour, and appeared to glow and sparkle in a wonderful manner. The phenomenon was visible for about two scconds, and lighted up everything around me. The night was fne and clear, with a decidedly frosty air, and there was a light, steady brecze blowing from the north-west at the time." On the same subject our Dunbar correspondent writes: 'A very brilliant meteor was observed here about eleven o'clock on Saturclay night. When first seen, the meteor had the appearance of a star of the first magnitude. As it approached, however, it gradually increased in size until it assumed the appearance of a ball of five or six inches in diameter, and changing its colour from a pale silvery white to a bright blue flame. As it still increased, sparlss seemed to be emitted from the circumference, giving it the appearance of being surrounded with a peculiar halo of dense silvery rays. It continued in this state for a second or two, and then shot across the heavens in a southerly direction, the ball increasing in brilliancy as it travelled, and leaving behind it a long train of lurid-coloured flame. From the time it was first seen approaching until it vanished about five or six seconds elapsed. The night was clear and cold at the time.'”

\section{THE GRESHAM LECTURES}

THE Lectures (three in number) were delivered by $\mathrm{Dr}$. Symes Thompson, during the past week, at the Gresham College, Basinghall-street. The first was occupied with the consideration of Cough, an account being given of its etiology varieties, and general principles of treatment. The second was devoted to Tonics; whilst of the third, which treated of Climate and Health Resorts, we give an epitome as likely to prove interesting to some of our readers. Dr. Thompson remarked that the Romans very enrly discovered the use of mineral waters, as shown by many of their relics being found in the neighbourhood of such springs; whilst at Wiesbaden, tablets have been found with votive inscriptions. Some of the more common ingredients of mineral waters were then described, and their chemical properties demonstrated, including carbonic acid, iron, sulphuretted hydrogen, \&c. The properties of ozone were then discussed in connection with pure air, and the lecturer passed on to the consideration of climate and health resorts, and said that it was a great mistake to suppose that any particular place was the best for a particular malady, for there is no specific action in the air of any place; and the physician, in recommending a resort to patients, had regard to the kind of climate there found, a dry climate being suitable for most bronchial membranes, and a moist climate for the reverse state of the membranes, and an approximation to such different climates can be obtained in our rooms. If the patient be feverish and excitable, he should be sent to an exciting varied climate; or, if languid and torpid, not to a quiet, mild, uniform climate. These two kinds of climate are obtainable at the south of France; for at Nice the climate is bright and exciting, while in the neighbourhood of the Pyrenees, at Pan, the atmosphere is very still, and eminently suitable to patients suffering from imitable membranes. The great advantage gained by persons going abroad is no doubt the regular daily outdoor exercise, not obtainable in the varied winter of our island, but found in Algiers, Riviera, Mentone, Nice, \&c., at that season. Together with exercise may be linked the advantage derived from breathing pure air. There are, however, many places in England where almost the same benefit may be enjoyed. It was the former practice in cases of lung-disease, to shut up patients in close rooms, with fire burning, all through the winter, the consequence being that they became like hothouse plants, and on the first exposure to the open air in spring all these advantages were lost. Acting on the same principle, consumptive patients up to 20 years ago were sent to Madeira. Three years ago the inhabitants of Madeira, wishing to re-establish the value of their climate in lung-disease, solicited the authorities of the Brompton Hospital for Consumption to send them out patients as a matter of experiment. Twenty patients were sent out, and only those who were likely to be benefited by the climate of Madeira, being all in an advanced stage of lung-disease. Of this number I patient died suddenly, although up to the time of his death he seemed to be benefiting by the change; 4 were worse; 6 were stationary, and 7 were markedly benefited; 2 very much benefited. This has been regarded by some as unsuccessful ; but Dr. Thompson was of different opinion, and thought it indicated that Madeira is a useful climate in certain cases. Since Madeira has been abandoned there has been a revulsion of feeling in favour of Canada as a resort for consumptives, but that this is no new doctrine is seen from the fact that the value of cold climates for consumption was advocated by Baron Larrey, Napoleon Bonaparte's physician. There are disadvantages as well as advantages in the most favoured health resorts; such as the dry, hot " mistral" of Nice, or the dry, dusty " brickfielder" of Melbourne, -winds which patients dislike as much as our east wind. Purity of air or $a b$ sence of dust is of very great importance; and for this reason it is now the practice to send patients suffering from chest-disease for a long sea-voyage. It constantly happens that sick peoplein whom the disease is far advanced-press their medical men to send them on a sea-voyage; but in their case the remedy has come too late, and so it happens that the death-rate at Melbourne is exceedingly high-more than half the deaths being due to consumption. Dampness favours consumption; so that dry air is another clesideratum which can be obtained at certain altitudes -so that in certain districts it is found possible to resort to mountain-tops, where consumption does not occur. In the neighbourhood of the equator the so-called "immunity-level" is at a height of 9,000 feet ; at Algiers, 6,000 feet ; at London, 3,000 feet. The chief resorts in Europe are the Swiss mountains, where English people often go to spend the winter, in perpetual snow, but yet in an atmosphere so pure and clear that the most delicate invalids can go out in the open air. In Norway, Russia, \&c., the immunity-level is only $\mathrm{I}, 000$ feet above the sea.

\section{SCIENTIFIC SERIALS}

THE May number of the Fournal of Botany, British and Foreign, commences with the first part of a Clavis Agaricinonum by the well-known fungologist, $\mathrm{Mr}$. Worthington Smith. The general classification of the Agarics adopted by Fries and Berkeley is followed; but several new sub-genera are proposed. An ingenious tabular view accompanies the paper, presenting the salient features of the series and sub-genera of this vast genus at a glance. Dr. Seemann continnes his revision of the natural order Bigroniacet; while the Hon. J. L. Warren contributes a paper on a sub-division of Rubus, a most intricate genus, to which he has paid special attention; and Dr. H. Trimen a clescription of a new British Callitriche. Other short notes and notices fill up the number, which maintains the interest for British botanists especially, promised on the commencement of the new series.

The Reaue des Cours Scientifiques for April 23rd contains a report of an interesting address delivered before the University of Berlin, by M. du Bois Reymond on the Organisation of Universities; the conclusion of F'otherly's address to the Hunterian Society, and report of a lecture by M. Claude Bernard, on Suffocation by Charcoal. The number for April zoth is entirely occupied by M. Bouley's lecture at the Sorbonne, on Madness, and the conclusion of $M$. Bernard's lecture. 